\title{
O PROFISSIONAL DA INFORMAÇÃO E A DRAMATURGIA INFANTIL: ESTUDO SOBRE A PRODUÇÃO CIENTÍFICA EM PERIÓdICOS DA CIÊNCIA DA INFORMAÇÃO ENTRE 2000 E 2011
}

THE INFORMATION PROFESSIONAL AND CHILDREN'S DRAMATURGY: STUDY ON SCIENTIFIC PRODUCTION IN INFORMATION SCIENCE JOURNALS BETWEEN 2000 AND 2011

EL PROFESSIONAL DE LA INFORMACIÓN E LA DRAMATURGIA INFANTIL: ESTUDIOS SOBRE LA PRODUCCIÓN CIENTÍFICA EM PERIÓDICOS DE LA CIÊNCIA DE LA INFORMACIÓN ENTRE 2000 Y 2011

${ }^{1}$ Clarice Fortkamp Caldin, ${ }^{1}$ Deyse Soares

${ }^{1}$ Universidade Federal de Santa Catarina

Correspondência

${ }^{1}$ Clarice Fortkamp Caldin

Universidade Federal de Santa Catarina

Florianópolis, SC

E-mail: clarice.fortkamp.caldin@ufsc.br

ORCID: http://orcid.org/0000-0001-7160-6796

Submetido em: 26-04-2016

Aceito em: 07-03-2017

Publicado: 03-04-2017

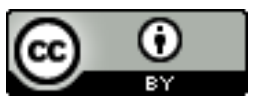

JITA: AC. Relationship of LIS with other fields. 
RESUMO: Trata da produção científica em periódicos sobre a atuação do profissional da informação na dramaturgia infantil no período compreendido entre 2000 e 2011. A Ciência da Informação é uma ciência social. Como tal, deve voltar-se para a sociedade (mundo dos homens) e aplicar todas as formas de conhecimento (entre eles o artístico). Esse artigo tem como objetivo investigar, por meio da produção bibliográfica na área de Ciência da Informação, o envolvimento dos bibliotecários em especial e dos profissionais da informação com a dramaturgia infantil. A pesquisa foi exploratória, qualitativa, com o uso da analise bibliográfica como técnica para a coleta de dados. O pequeno número de artigos encontrados indica que o profissional da informação necessita às vezes extrapolar os limites da técnica e adentrar no terreno da arte, da expressividade. Há que mesclar ações profissionais/científicas com ações profissionais/artísticas. Lembra-se que a arte sempre foi precursora da ciência, da técnica e da tecnologia. Concluiu-se: os profissionais da informação precisam estar cientes do impacto da dramaturgia no imaginário infantil.

PALAVRAS-ChAVE: Profissional da informação. Bibliotecário. Teatro. Artes. Literatura infantil. Ficção.

ABSTRACT: This study deals with the scientific production in journals, on the performance of the information professional in children's dramaturgy in the period between 2000 and 2011. Information Science is a social science. As such, it must focus on society (world of men) and apply all forms of knowledge (among them the artistic). This article aims to investigate, through the bibliographic production in the area of Information Science, the involvement of information professionals, librarians in particular, with children's dramaturgy. The research was exploratory, bibliographical and qualitative. The small number of articles found indicates that the information professional sometimes needs to extrapolate the limits of technique and enter the art field. It is necessary to merge professional/scientific actions with professional/artistic actions. One remembers that art has always been precursor of science, technique and technology. In conclusion, information professionals need to be aware of the impact of dramaturgy in children's imagination.

KEYWORDS: Professional information. Librarian. Theater. Art. Children's literature. Fiction.

RESUMEN: Trata de la producción científica en los periódicos sobre la actualización del profesional de la información en la dramaturgia infantil no período comprendido entre 2000 y 2011. A Ciencia de la Información sobre una Sociedad Social. Como tal, debe volver a formar parte de una sociedad (mundo dos hombres) y aplicar todas las formas de conocimiento (entre ellos el arte). Este artículo tiene como objetivo investigar, por medio de la producción bibliográfica en el área de la Ciencia de la Información, el envolvimiento de los bibliotecarios en especial y los profesionales de la información con una dramaturgia infantil. A pesquisa para exploración, cualitativa, con o uso de analítica bibliográfica como técnica para una coleta de datos. El número de artículos encontrados indica que el profesional de la información necesita a veces extrapolar los límites de la técnica y adentrar ningún terreno de la arte, de la expresividad. Que mesclar acciones profesionales / científicas con acciones profesionales / artísticas. Se acuerda que un arte siempre fue precursora de la ciencia, la técnica y la tecnología. Se concluye: los profesionales de la información cuentan con el impacto de la dramaturgia no imaginario infantil.

PALABRAS ClAVE: Profesional de la información. Bibliotecario. Teatro. Artes. Literatura infantil. Ficción.

\begin{tabular}{c|c|c|c|c|c}
\hline (C) RDBCI: Rev. Digit. Bibliotecon. Cienc. Inf. & Campinas, SP & v.15 & n.2 & p. 308-323 & maio/ago. 2017 \\
\hline
\end{tabular}




\section{INTRODUÇÃO}

O presente artigo é fruto de um projeto de pesquisa desenvolvido ao longo dos anos de 2012 a 2014, por uma professora pesquisadora e sua monitora, com o objetivo de investigar por meio da produção bibliográfica na área de Ciência da Informação e subárea Biblioteconomia, o envolvimento dos bibliotecários em especial e dos profissionais da informação com a dramaturgia infantil.

Registra-se que a pesquisadora observou, ao longo dos anos de docência, principalmente ao ministrar a disciplina Biblioterapia, optativa da matriz curricular do curso de graduação em Biblioteconomia, a preferência dos acadêmicos em valer-se da dramatização nas atividades biblioterapêuticas em instituições voltadas ao público infantil, tais como creches, escolas ou orfanatos. Também na disciplina Análise da Informação literária para crianças, ministrada nos cursos de mestrado e doutorado em Ciência da Informação, percebeu o interesse dos alunos na dramatização de textos literários infantis. Além disso, em palestras, seminários e cursos ministrados, verificou que os profissionais da informação, de maneira geral, carecem de estudos teóricos que embasem a prática da arte cênica como uma das possibilidades de incentivar a leitura em bibliotecas escolares, públicas e infantis.

Esclarece-se que do ponto de vista de seu objetivo, a pesquisa se configurou como exploratória; do ponto de vista dos procedimentos técnicos, como bibliográfica e do ponto de vista da abordagem do problema, como qualitativa.

Ressalta-se que a Ciência da Informação é uma ciência social. Como tal, preocupa-se com o ser humano, com a forma com que ele recebe, assimila, interpreta e dissemina a informação. Esclarece-se que a dramaturgia infantil pode ser considerada uma nova forma de mediar a informação - entre adultos e crianças, entre crianças e crianças. Como arte, permite a criatividade e a interatividade com os atores sociais.

Como estrutura do artigo tem-se: a) referencial teórico; b) metodologia do estudo; c) apresentação e análise dos artigos encontrados; d) conclusão; e) referências.

\section{REFERENCIAL TEÓRICO}

Martins (2007, p. 138, 144) realizou um estudo dos fundamentos sociais da Ciência da Informação e, baseado em Capurro, Shera e Wersig, inferiu:

Capurro tem sido um autor que se preocupou em fundamentar a relação entre hermenêutica e Ciência da Informação. [...] Capurro tenta ampliar a aplicação da hermenêutica para além da recuperação da informação, alcançando a dimensão das relações humanas, em busca de um entendimento do "ser no mundo em relação aos outros." [...] Temos na Epistemologia Social de Shera a preocupação com a relação face ao conhecimento, estabelecida entre quem disponibiliza e quem busca as

\begin{tabular}{|c|c|c|c|c|c|}
\hline (C) RDBCI: Rev. Digit. Bibliotecon. Cienc. Inf. & Campinas, SP & $\mathrm{v} .15$ & n.2 & p. $308-323$ & maio/ago. 2017 \\
\hline
\end{tabular}


informações (centrado no ser humano e na sociedade como um todo). Na abordagem de Wersig temos a ideia de compreensão relacionada à maneira pela qual o ser humano utiliza ou compreende o conhecimento.

Assim, a Ciência da Informação volta-se para a informação e o conhecimento "situados", ou seja, atrelados ao contexto social do sujeito. Cabe lembrar que a informação literária é também uma forma de compreender e interpretar o mundo. Nesse sentido, o teatro (texto e espetáculo) é uma linguagem que agrega conhecimentos solidificados pela tradição cultural, mas que permite inferições na medida em que cada um processa as informações por ele disponibilizadas.

Araújo e Dias (2005, p.121) ao tratar da função gerenciamento em uma biblioteca, afirmam que no contexto da Sociedade da Informação a atuação profissional: "exige uma postura de criatividade, de renovação constante e de disposição para enfrentar desafios diários."

Em outras palavras: o desafio é o tecnológico, a presença marcante da máquina no mundo dos homens. Esquece-se que o desafio maior é o entendimento do ser humano, suas carências, desejos, expectativas, interesses. Esquece-se também que a Ciência da Informação é uma ciência social e aplicada. Como tal, deve voltar-se para a sociedade (mundo dos homens) e aplicar todas as formas de conhecimento (entre eles o artístico) no afã de não apenas difundir informações, mas também formar conhecimento.

Saracevic (1996, p. 41,42) aponta a: "natureza mutante" da Ciência da Informação; cita como uma das características da sua existência e evolução o compartilhamento com outros campos; afirma que a Ciência da Informação é: "por natureza, interdisciplinar" e que: "A CI teve e tem um importante papel a desempenhar por sua forte dimensão social e humana, que ultrapassa a tecnologia."

Muito embora Saracevic (1996) examine as relações multidisciplinares da Ciência da Informação com os campos da Biblioteconomia, Ciência da Computação, Ciência Cognitiva e Comunicação, reconhece que os problemas enfrentados pela sociedade contemporânea não podem ser sanados apenas pela tecnologia.

A esse mister se presta a dramaturgia - como informação literária, como arte, como expressividade, responde à necessidade humana de: "dar forma à fantasia, inclusive (talvez sobretudo), a fim de compreender melhor a realidade" (Candido,1995, p. 15).

E Sunderland (2005, p. 21) assevera que se: “as palavras literais expressassem plenamente o que sentem os seres humanos, não haveria necessidade de música, pintura, teatro ou poesia."

Não poderia deixar de ser citado Aristóteles (2006, cap. IV) sobre a origem da poesia e seus diferentes gêneros: o filósofo advoga que a imitação é inerente ao ser humano e essa

\begin{tabular}{|c|c|c|c|c|c|}
\hline (C) RDBCI: Rev. Digit. Bibliotecon. Cienc. Inf. & Campinas, SP & V.15 & n.2 & n 308-323 & maio/ago. 2017 \\
\hline
\end{tabular}


tendência se manifesta desde os primeiros anos de vida; considera-a fonte de conhecimento e prazer e a origem do gênero poético.

Cabe registrar que o teatro, na sua origem grega e em especial a tragédia, servia para fins educativos ao povo, como purgação, como uma maneira de purificar o ser humano, como uma potência catártica, como uma plataforma ao anseio da imitação presente no indivíduo.

Aristóteles (2006, cap.V) atribui à comédia: “a imitação de maus costumes, não contudo de toda sorte de vícios, mas só daquela parte do ignominioso que é o ridículo", o que não era indicado às crianças justamente pelo caráter licencioso e nada didático da comédia. A tragédia, por outro lado, entendida como: "imitação de uma ação importante e completa" das personagens é: "um belo espetáculo oferecido aos olhos", haja vista que tais personagens apresentam bom caráter digno de ser imitado; de fato, explicita que a tragédia é a imitação de "ações, da vida, da felicidade e da infelicidade" (pois a infelicidade resulta também da atividade) sendo o fim que se pretende alcançar o resultado de uma certa maneira de agir, e não de uma maneira de ser (ARISTÓTELES, 2006, cap.VI).

Conquanto Aristóteles tenha concedido status educativo à tragédia, não obliterou seu aspecto estético. Ao contrário, apresenta detalhes da sua encenação, caracteres, fabulação e admira os poetas trágicos que organizam o texto e o espetáculo com fatos bem ordenados.

Lembra Mendes (2001) que a dança, considerada também arte imitativa, era parte integrante dos rituais religiosos e do teatro gregos, da educação e diversão da civilização helênica; tinha um caráter respeitável, pois se acreditava que ela tornava os homens melhores - por isso era acessível a todos.

Cumpre registrar que o espetáculo cênico, desde os primórdios, valeu-se da dança e da música, que complementavam a performance dos atores. Quando se trata da dramaturgia infantil, dança e música são mais que complementos à apresentação teatral; de fato, aumentam o poder de sedução do texto encenado, agilizam a catarse e permitem associações entre movimento ritmado, som melodioso e fala.

Arcoverde (2008, p. 602) discorre sobre a função pedagógica do teatro, e lembra, apropriadamente, que: “o teatro é arte, arte que precisa ser estudada não apenas em níveis pedagógicos, mas também como uma atividade artística que tem as suas características como tal."

Destarte, mesmo que a função pedagógica se encontre embutida no trabalho cenográfico, ela não ofuscar a função estética. Como a literatura infantil, o teatro para crianças iniciou atrelado ao conceito de aprendizagem utilitária e de moralidade contextualizada a cada época. 
Assim, mesmo que a preocupação adulta penda para a exploração do didático e do informativo em qualquer formato de texto para crianças, há que se mudar esse parâmetro: literatura (prosa, poesia, texto dramático) é ficção, é expressividade. Sem impor, por metáforas, a literatura com certeza educa (e não ensina - pois não é essa sua função). A efabulação, por si só, contém sugestões de comportamentos apropriados; não é necessário destacá-los explicitamente.

Ferreira (2010, p. 19) traz à tona as palavras de Dib Carneiro Neto, crítico de teatro infantil que condena o didatismo presente nas peças apresentadas às crianças:

\begin{abstract}
Dentre as práticas e discursos levantados por Carneiro Neto (2003, p. 10) como perniciosas ao teatro para crianças e que, segundo o crítico, subestimam as capacidades infantis, estão 'o excesso de intenções didáticas', sobre o qual diz que 'não é preciso ser explícito, criança é capaz de entender sugestões, simbologias. Arte é feita de alegorias, de metáforas. Estranheza é saudável. Explicar é redutor, sempre. Subestima a criança, facilita demais' e a obsessão pela lição de moral', sobre a qual escreve o crítico: 'teatro infantil não tem a obrigação de encerrar em si uma bela lição construtiva.
\end{abstract}

Em outros termos: o teatro na educação pode contemplar a cognição, a apreensão de conteúdos informativos, o senso crítico, mas sem perder de vista a ludicidade, a espontaneidade, a imaginação. Dessa feita, a transmissão de valores que a peça teatral enseja deve ser realizada suave e metaforicamente, permitindo à criança espectadora o usufruto do belo. Assim como a literatura infantil atrela-se à pedagogia, o teatro na escola pende à transmissão de ensinamentos; por vezes esquece-se que o teatro (seja qual for seu enquadramento) foge do rigor da ciência e instala-se nos quartos da arte. Justamente por esse motivo possibilita o jogo, o brincar, a admiração, o espanto.

Silva (2007, p. 12) advoga que: "o teatro na educação tem como proposta básica promover atividades de expressão lúdica e momentos em que os alunos possam dar asas à sua imaginação desde a Educação Infantil"; acrescenta exercícios baseados em sua atuação com crianças e adolescentes que promovam: relacionamento, espontaneidade, imaginação, observação, percepção; finaliza o artigo justificando a utilização de jogos teatrais no cotidiano das escolas.

E Valentim (2002) esclarece que no IV Encuentro de Directores de Escuelas de Bibliotecologia y Ciencia de la Informacion del Mercosur, realizado em Montevideo em 2000, definiu-se as competências para o profissional da informação como sendo: competências de comunicação e expressão; competências técnico-científicas; competências gerenciais e competências sociais e políticas. Nessa última categoria, aparece como desejável a interatividade com diversos atores sociais (educadores, por exemplo). Esclarece, ainda, que no Brasil, a Proposta de Diretrizes Curriculares do Ministério da Educação (MEC) aponta como necessárias à formação profissional da informação a criatividade e a implementação de novas maneiras de mediar a informação.

\begin{tabular}{l|c|c|c|c|c|}
\hline C C RDBCI: Rev. Digit. Bibliotecon. Cienc. Inf. & Campinas, SP & v.15 & n.2 & p. 308-323 & maio/ago. 2017 \\
\hline
\end{tabular}


Então, o profissional da informação precisa às vezes extrapolar os limites da técnica e adentrar no terreno da arte, da expressividade. Há que mesclar ações profissionais/científicas com ações profissionais/artísticas. É necessário, entretanto, não perder de vista o caráter ímpar da arte - a expressividade, o impacto no imaginário, o potencial transformador nos indivíduos, e, sobretudo, a fruição estética. Assim, a dramaturgia infantil, se coordenada ou executada por bibliotecários, pode ser utilizada com um meio educativo, mas não deve ser essa sua finalidade. O fim último da atualização de um texto dramático é causar prazer, estimular o imaginário, produzir a catarse.

\section{METODOLOGIA DO ESTUDO}

A pesquisa, aprovada pelo colegiado do Departamento de Ciência da Informação da Universidade Federal de Santa Catarina, consistiu na busca em revistas da área da Ciência da informação/Biblioteconomia, abrangendo os anos de 2000 a 2011, utilizando como buscadores os termos: profissional da informação, bibliotecário e teatro infantil.

A pesquisa deveria incidir sobre 27 revistas, que foram selecionadas com a visita à "home info", OFAJ, (http://www.ofaj.com.br/colunas_conteudo.php?cod=553), e no texto de Cunha (2010) que faz o levantamento das revistas da área. Entretanto, a pesquisa contemplou apenas em 19 revistas, por diversos fatores: repositórios institucionais contendo somente informativos da área; revista em que o ano de abrangência era inferior ao ano proposto na pesquisa; endereços que remetiam a páginas de pesquisa fora da área; revista com foco em outra área do conhecimento.

As revistas pesquisadas foram:

a) Informação \& Sociedade (http://www.ies.ufpb.br);

b) Encontros Bibli (http://www.periodicos.ufsc.br/index.php/eb);

c) Transinformação (https://www.puc-campinas.edu.br/periodicocientifico);

d) Biblionline (http://periodicos.ufpb.br/ojs2/index.php/biblio/index);

e) Biblos (http://www.seer.furg.br/ojs/index.php/biblos);

f) Brazilian Journal of Information Science (http://www2.marilia.unesp.br/revistas/index.php/bjis/index);

g) Ciência da Informação (http://revista.ibict.br/ciinf/);

h) Comunicação \& Informação (http://www.revistas.ufg.br/index.php/ci);

i) Em Questão (http://www.seer.ufrgs.br/index.php/EmQuestao);

j) Inclusão Social (http://revista.ibict.br/inclusao/index.php/inclusao/index);

k) Informação \& Informação (http://www.uel.br/revistas/uel/index.php/informacao);

1) Liinc em Revista (http://revista.ibict.br/liinc/index.php/liinc/);

m) Perspectivas em Ciência da Informação

(http://portaldeperiodicos.eci.ufmg.br/index.php/pci/index);

n) Ponto de Acesso (http://www.portalseer.ufba.br/index.php/revistaici/index);

o) Revista Brasileira de Biblioteconomia e Documentação

(http://www.febab.org.br/rbbd/ojs-2.1.1/index.php/rbbd/index); 
p) Revista Digital de Biblioteconomia e Ciência da Informação (http://periodicos.sbu.unicamp.br/ojs/index.php/rdbci/ );

q) Revista Ibero-Americana de Ciência da Informação

(http://seer.bce.unb.br/index.php/RICI/);

r) DataGramaZero (http://www.dgz.org.br)

s) Revista ACB: Biblioteconomia em Santa Catarina (http://revista.acbsc.org.br/racb).

Somando todas as revistas pesquisadas, contabilizou-se: a) com o buscador profissional da informação encontrou-se 469 artigos; b) com o buscador bibliotecário encontrou-se 367 artigos; com o buscador teatro infantil encontrou-se 2 artigos. Entretanto, para a pesquisa em foco, 2 artigos considerados pertinentes com o termo bibliotecário foram encontrados: 1 artigo na revista Biblos e 1 artigo na revista Perspectivas em Ciência da Informação. Na revista EmQuestão foram considerados pertinentes 2 artigos, sendo 1 com o buscador profissional da informação e 1 com o buscador teatro infantil, sendo este último em espanhol, indexado em revista brasileira.

Para maior esclarecimento, apresenta-se o quadro a seguir.

QUADRO 1. Relação dos artigos encontrados - 2000 a 2011

\begin{tabular}{|c|c|c|c|c|}
\hline Revista & Termo de busca & Autores & Título & v./n./ano \\
\hline BIBLOS & Bibliotecário & $\begin{array}{l}\text { MARTINS, } \\
\text { Maritza Silveira; } \\
\text { CIPOLAT, } \\
\text { Sabrina }\end{array}$ & $\begin{array}{l}\text { O bibliotecário como } \\
\text { agente socializador na } \\
\text { disseminação da } \\
\text { informação sobre meio } \\
\text { ambiente: relato de } \\
\text { experiência }\end{array}$ & v. 18, n. 2,2006 \\
\hline Em Questão & $\begin{array}{l}\text { Profissional da } \\
\text { informação }\end{array}$ & $\begin{array}{c}\text { SIQUEIRA, } \\
\text { Denise da Costa } \\
\text { de Oliveira; } \\
\text { ALVES, Roberta } \\
\text { de Souza } \\
\text { Arcoverde }\end{array}$ & $\begin{array}{l}\text { Corpos, utopias: dança } \\
\text { e teatro como } \\
\text { alternativas de } \\
\text { comunicação e } \\
\text { cidadania }\end{array}$ & v.14, n. 1,2008 \\
\hline Em Questão & Teatro infantil & $\begin{array}{c}\text { GIRALDO } \\
\text { GIRALDO, } \\
\text { Yicel Nayrobis; } \\
\text { ROMÁN } \\
\text { BETANCUR, } \\
\text { Gloria Elena }\end{array}$ & $\begin{array}{l}\text { La biblioteca pública } \\
\text { como mediadora en la } \\
\text { construcción de la } \\
\text { ciudadanía }\end{array}$ & v.17, n. 1,2011 \\
\hline $\begin{array}{c}\text { Perspectivas } \\
\text { em da } \\
\text { Informação } \\
\text { Ciência }\end{array}$ & Bibliotecário & $\begin{array}{c}\text { FARIAS, } \\
\text { Christianne } \\
\text { Martins; } \\
\text { VITORINO, } \\
\text { Elizete Vieira }\end{array}$ & $\begin{array}{c}\text { Competência } \\
\text { informacional e } \\
\text { dimensões da } \\
\text { competência do } \\
\text { bibliotecário no } \\
\text { contexto escolar }\end{array}$ & v.14, n.2, 2009 \\
\hline
\end{tabular}

Fonte: As autoras, pesquisa bibliográfica 


\section{APRESENTAÇÃO E ANÁLISE dOS ARTIGOS ENCONTRADOS}

O primeiro artigo analisado foi o de autoria de Maritza Silveira Martins e Sabrina Cipolat, ambas bibliotecárias, intitulado: $O$ bibliotecário como agente socializador na disseminação da informação sobre meio ambiente: relato de experiência.

Trata-se de um projeto desenvolvido em 2005 pelas duas bibliotecárias em parceria com outras colegas do curso de Biblioteconomia da FURG; apresenta a dramaturgia infantil como meio de conscientizar crianças do ensino fundamental da Escola Municipal Barão de Cerro Largo (Rio Grande -RS) sobre a importância da preservação da natureza.

De acordo com Martins e Cipolat (2006) o projeto se configurou como material didático não-convencional, que consistiu na criação de uma trilha ecológica com cenários sobre a natureza morta e natureza viva. O primeiro cenário mostrava uma floresta destruída pelo desmatamento e pelas queimadas, animais transmissores de doenças e lixo; o segundo cenário mostrava uma lagoa com água poluída, peixes mortos e muito lixo - ambos retratavam a natureza morta. $O$ terceiro cenário era uma representação da natureza viva, com a floresta fervilhante de vida animal e vegetal; o quarto cenário, também da natureza viva, representava a lagoa limpa, pululando com os animais aquáticos saudáveis.

As autoras do projeto valeram-se de personagens ficcionais conhecidas das crianças. Chapeuzinho Vermelho conduz a narrativa, convidando os alunos à trilha ecológica e apontando os perigos da destruição da natureza. Juntam-se a ela o Lobo Mau e o Patinho Feio, que sofreram as consequências do lixo abandonado na floresta e na lagoa. A seguir, aparece o culpado dessa situação: Pinóquio, que, sem ter noção do mal que causava, jogava restos de seu lanche ao longo do caminho. Após ser admoestado, Pinóquio se arrepende de sua atitude e auxilia na recolha de todo o lixo. Assim, recupera-se o ecossistema e a Pequena Sereia e Branca de Neve podem retornar para suas casas. Nas considerações finais, Martins e Cipolat (2006, p. 188, 189) salientam a satisfação em ter alcançado os objetivos:

\footnotetext{
relacionar o 'fazer biblioteconômico' com o tema meio ambiente; mostrar o papel do bibliotecário como agente socializador e disseminador da informação sobre meio ambiente na formação inicial de cidadãos conscientes, e estimular na criança a observação crítica, esperando dela respostas e ações para uma mudança de comportamento perante a conservação da natureza, foram as metas traçadas e felizmente alcançadas com este projeto. [...] devido ao sucesso do projeto, a rede local de televisão fez uma reportagem apresentando o projeto no momento de sua aplicação, que foi exibida no deu telejornal para todo o município.
}

Conforme observado ao longo do artigo, a intencionalidade pedagógica esteve presente em toda a peça - e isso agradou os adultos - estudantes de biblioteconomia, diretora da Escola (inicialmente a pretensão era desenvolver o projeto apenas com alunos da primeira série e a direção da escola solicitou que fosse executado também com alunos da segunda à quarta série do ensino fundamental) e a mídia televisiva. Mesmo sendo louvável a promoção do

\begin{tabular}{c|c|c|c|c|c}
\hline (C) RDBCI: Rev. Digit. Bibliotecon. Cienc. Inf. & Campinas, SP & v.15 & n.2 & p. 308-323 & maio/ago. 2017 \\
\hline \multicolumn{6}{c}{$[316]$}
\end{tabular}


comprometimento com o ecossistema, há que se priorizar o ludismo, a brincadeira, o jogo de faz-de-conta, o estímulo à imaginação criadora. Nas considerações finais Martins e Cipolat (2006) afirmam que sensibilizaram as crianças por meio da articulação da fantasia com a realidade.

Infere-se que os objetivos pretendidos no projeto foram além dos desejados, pois a peça contribuiu não apenas para atitudes de preservação da natureza, mas para a divulgação de historias infantis e mostrou o poder de sedução da literatura, em especial, o espetáculo cênico. Isso nos remete a Candido (1995), que reforça o papel da informação literária - pelas vias da fantasia - para o enfrentamento dos problemas da realidade.

O segundo artigo analisado, de autoria de Denise da Costa de Oliveira Siqueira (docente, doutora em Comunicação) e Roberta de Souza Arcoverde Alves (graduada em Comunicação Social), intitulado Corpos, utopias: dança e teatro como alternativas de comunicação e cidadania, apresenta o teatro como instrumento de crítica à sociedade.

Segundo as autoras: "se considerarmos a política em cada ato da vida cotidiana e se considerarmos a arte parte desse cotidiano, entendemos que a dança e o teatro podem ser formas de manifestação política e meios de comunicação" (SIQUEIRA; ALVES, 2008, p. 64).

O estudo incide sobre três grupos: Companhia Étnica de Dança e Teatro (Rio de Janeiro), Teatro Novo (Niterói) e Periferia em Ação (São Gonçalo). O primeiro grupo preocupa-se com a inclusão social de jovens negros; o segundo, com jovens portadores da síndrome de Down e o terceiro, com jovens de baixa renda.

Siqueira e Alves (2008) valeram-se, como metodologia, da observação, entrevistas, pesquisa bibliográfica sobre teatro e dança, que culminaram na discussão entre a teoria e a prática. Destacam que a produção teatral é mais relevante do que o produto, ou seja, a ação, o fazer, o participar tem peso maior do que a peça em si. Priorizam a formação da cidadania, a inclusão social de grupos menos favorecidos, a disseminação de informações, a mudança de postura perante a realidade, a comunicação e a educação. Ao assim fazer, consideram o teatro e a dança um meio para um fim e não uma proposta estética. Isso se coaduna com a formação de ambas em Comunicação, conquanto utilizem também linguagem da Ciência da Informação, como por exemplo, denominam os participantes dos grupos de "mediadores culturais" que "filtram" a informação antes de transmiti-la.

Muito embora os projetos pretendam a inserção social, promovem também a expressividade, pois permitem que a comunidade envolvida valorize a arte, entendida como transgressora, o que de fato é. Dança e teatro, manifestações artísticas, burlam o tradicional, o estabelecido, e abrem as comportas do inusitado. 
Acerca da Companhia Étnica de Dança e Teatro Siqueira e Alves (2008, p. 68) registram que é: "um projeto artístico", "social”, "formador/educador", uma "intervenção estético-cultural na favela"; a "dança e o corpo são os meios que viabilizam o projeto de mostrar aos jovens e crianças que há outros caminhos que aquele da marginalidade social."

Sobre o Grupo Teatro Novo, esclarecem que as: "peças possuem caráter informativo, trabalhando temas como cidadania, preconceito, trabalho, segurança no trânsito"; com "cenário simples" e "linguagem clara e objetiva, acessível ao público", na maioria crianças com síndrome de Down; esclarecem também que: "vinte participantes frequentam o grupo em aulas de teatro e dança" (Siqueira; Alves, 2008, p. 70).

No que tange ao Grupo Periferia em Ação a proposta é apresentar um Teatro do Oprimido, que segundo Boal (2003 apud SIQUEIRA; ALVES, 2008, p. 72), significa: "apresentação de situações que não fazem parte do desejo dos oprimidos e que são impostas por um opressor, gerando conflito. No lugar de esperar a mudança da realidade, os próprios oprimidos devem buscá-la. " Para atingir esse objetivo, o teatro é apresentado não só como forma de cultura, mas como um espaço de conscientização da necessidade de mudanças sociais; há sempre intervenção de um espectador que é convidado a assumir uma personagem e que incita ao debate sobre os temas apresentados: sexualidade, gravidez, drogas, violência familiar; atores e dançarinos se empenham em apresentar uma: "arte engajada" que: "assume importante papel informativo para seus próprios participantes e depois, para as audiências" (SIQUEIRA; ALVES, 2008, p.74).

Muito embora o artigo em tela explane o papel da dramaturgia nos três projetos, menciona a dança apenas de passagem. Mas é bom lembrar o caráter estético da dança desde os seus primórdios, quando o ritmo era atrelado ao mito e ao rito das sociedades primitivas.

Segundo Mendes (2001, p. 10): "Esteticamente a dança pode ser considerada como a mais antiga das artes, a mais capaz de exprimir tanto as fortes quanto as simples emoções sem o auxílio da palavra."

Assim, pode-se dizer que a dança supre o que as palavras às vezes não são capazes de expressar, pois valendo-se do simbolismo permite uma comunicação das emoções e não da razão. E muito embora os referidos projetos estejam fortemente vinculados à educação, não esquecem que tanto o teatro quanto a dança são formas de expressão artística e em essência a arte é expressividade.

O terceiro artigo analisado, de autoria de Yicel Nayrobis Giraldo Giraldo (bibliotecária, docente e doutoranda em Ciências Sociais) e Gloria Elena Román Betancur (docente e doutoranda em Ciências da Educação), intitulado La biblioteca pública como mediadora em la construcción de la cidadania, trata sobre as representações que as crianças têm da biblioteca 
pública na Colômbia e sobre o impacto que a biblioteca pode ter nas comunidades. Embora escrito em espanhol, foi publicado em revista brasileira.

As autoras se referem à metodologia utilizada como interpretativa, como o estudo dos significados e da linguagem como meio de entender e construir o mundo; esclarecem que as bibliotecas objeto do estudo foram: "Parque Biblioteca España", "Centro de Lectura de la Fundación Ratón de Biblioteca" e "Biblioteca Popular n. 2" (GIRALDO GIRALDO; ROMÁN BETANCUR, 2011, p. 214).

Explicitam que as crianças veem a biblioteca pública como um lugar de leitura aberto a todas as pessoas, sem restrições de qualquer natureza; percebem que a gratuidade de seus serviços favorece os de menor poder econômico; prezam o serviço de empréstimos de material bibliográfico; não atribuem a ela o papel de interventora nos problemas da comunidade, em especial o da violência social; registram testemunhos de crianças sobre as oportunidades que a biblioteca pública oferece no sentido de melhorar a leitura e a escrita, aumentar o vocabulário, aprender a respeitar o próximo, valorizar a família e a paz (GIRALDO GIRALDO; ROMÁN BETANCUR, 2011).

Conquanto as autoras tenham o cuidado de mostrar que a sociedade vê as crianças como desprovidas de competências para tomar decisões, apresentam argumentos em favor de que as mesmas possam opinar, pois encontram-se em processo de formação e é importante que sua dignidade e vontade sejam respeitadas; por isso defendem a biblioteca pública como um espaço de promoção da cidadania.

A dramaturgia aparece de passagem, apenas como uma das atividades realizadas pela biblioteca pública, dando-se ênfase ao estudo e à recuperação da informação. Tendo em vista a precariedade das bibliotecas escolares na Colômbia, as autoras justificam a ida à biblioteca pública com o fim primeiro de estudar e realizar as tarefas impostas pelos professores. Defendem a prática da leitura na biblioteca como um motor de transformação individual e social, mas não destacam o aprender teatro e a assistência a peças teatrais no espaço da biblioteca, muito embora mencionem que a mesma, como ambiente educativo, deveria promover tais atividades. $\mathrm{O}$ foco do artigo é mostrar as representações das crianças sobre a biblioteca pública como instituição social, como ambiente educativo e como cenário de socialização política. Entretanto, é bom lembrar as palavras de Arcoverde (2008, p. 602): “O teatro estimula o indivíduo no seu desenvolvimento mental e psicológico. "Assim, além da leitura, o teatro serve também como veículo socializador e gerador de reflexões.

O quarto artigo analisado, de autoria de Christianne Martins Farias (bibliotecária e mestre em Ciência da Informação) e Elizete Vieira Vitorino (docente, doutora em Engenharia de Produção) intitulado Competência informacional $e$ dimensões da competência do bibliotecário no contexto escolar salienta as dimensões técnica, estética, ética e política do bibliotecário escolar. Para o presente estudo, interessa apenas a dimensão estética.

\begin{tabular}{c|c|c|c|c|c|}
\hline (C) RDBCI: Rev. Digit. Bibliotecon. Cienc. Inf. & Campinas, SP & v.15 & n.2 & p. 308-323 & maio/ago. 2017 \\
\hline
\end{tabular}


No artigo em questão as autoras apresentam o bibliotecário escolar como um profissional da informação que deve se preocupar com a interação com os professores no intuito de facilitar o aprendizado dos alunos e ressaltam a importância de formação continuada do bibliotecário como forma de dar maior visibilidade a esse profissional.

Muito embora citem a função pedagógica da biblioteca escolar e entendam o bibliotecário como um agente de transformação e de mediação na sociedade da informação, apto a contribuir no planejamento curricular, não mencionam a dramaturgia como uma das competências e habilidades do bibliotecário, entendendo a competência estética como criatividade: uma possibilidade de: "antever os vários usos possíveis das informações coletadas e produzidas na escola” (FARIAS, VITORINO, 2009, p. 13).

Cabem aqui as palavras de Grazioli (2007, p.14):

\begin{abstract}
O sistema educacional aplicado nas escolas de maneira geral não contempla a arte teatral como atividade curricular relevante. Ao contrário, no decorrer dos últimos anos, tem-se falado muito na prática teatral escolar, mas se tem feito muito pouco para que ela aconteça de forma efetiva. Infelizmente, esta arte ainda não encontrou lugar nos programas de ensino, em razão de uma série de fatores, que vão desde o entendimento equivocado de sua função e importância no desenvolvimento do aluno até as questões econômicas que assolam o país e acabam afetando o segmento educacional.
\end{abstract}

No contexto da escola, ficam obliteradas as potencialidades expressivas do teatro para crianças como forma, também, de disseminar as informações.

Nesse sentido, o bibliotecário poderia contribuir oferecendo sugestões para inserção da dramaturgia infantil no currículo do ensino fundamental.

Entretanto, Farias e Vitorino (2009) não exploram esse filão. Isso é compreensível, pois as autoras investem nas transformações ocorridas na educação no contexto da Sociedade da Informação. Por esse motivo, focam na competência como um saber dinâmico e plural indispensável ao bom desempenho do bibliotecário escolar nas atividades voltadas ao ensino e à aprendizagem.

\title{
5 CONCLUSÃo
}

Os fundamentos sociais da Ciência da Informação priorizam as relações humanas tanto na produção quanto na recuperação e uso da informação como forma de compreensão do mundo e formação de conhecimento.

Cabe lembrar que a informação é situada, o que significa dizer, sofre o efeito da temporalidade, da subjetividade e da hermenêutica. Isso explica a evolução das ciências e das artes e o caráter interdisciplinar das várias áreas do conhecimento.

\begin{tabular}{c|c|c|c|c|c}
\hline (C) RDBCI: Rev. Digit. Bibliotecon. Cienc. Inf. & Campinas, SP & v.15 & n.2 & p. 308-323 & maio/ago. 2017 \\
\hline \multicolumn{5}{c}{$[320]$}
\end{tabular}


Nessa sociedade globalizada, tecnológica, os problemas do ser humano não diminuíram, como se esperava fosse acontecer. De fato, a rapidez com que se tornam obsoletas as ferramentas tecnológicas e o desafio diário de acompanhar as mudanças causam estresse em todas as categorias profissionais.

Mesmo o profissional da informação, que, presume-se, domine as técnicas, o "saberfazer", não fica imune à sensação de impotência ante a enxurrada de tecnologia com que se defronta; acresce que além de dominá-la, deve ser capaz de ensinar a outros (usuários, clientes) como fazê-lo.

Isso remete ao papel social e aplicado da Ciência da Informação: o profissional não lida apenas com máquinas, lida com pessoas e assim, além das competências técnico-científicas, deve possuir, também, competências de comunicação e expressão. Quando esse profissional atua na biblioteca escolar ou na biblioteca pública, a dramaturgia infantil é um excelente recurso para expor e transmitir ideias e sentimentos.

No primeiro, dentre os artigos analisados, observou-se que o teatro na educação tem primazia nas escolas, o que é coerente, haja vista que pretende formar as crianças. Entretanto, por vezes o utilitarismo obscurece o caráter lúdico e estético das peças encenadas. Notou-se, no segundo artigo, que o teatro nas comunidades carentes sempre se volta para o despertar da cidadania como maneira de conscientizar os indivíduos de suas carências e possibilidades de mudar o quadro social. No tocante ao relato das representações que as crianças têm da biblioteca pública na Colômbia, ficou nítido que apenas ocasionalmente o espaço da biblioteca se presta para atividades culturais, entre elas, a dramaturgia. Por fim, no artigo que trata da competência estética do bibliotecário, não há teoria ou relato de atividades de teatro como uma das formas de atuação do bibliotecário.

Presume-se que o número reduzido de artigos publicados sobre a importância da dramaturgia infantil se deve, em parte, às restrições impostas pela própria pesquisa, tanto no uso de buscadores com os termos profissional da informação, bibliotecário e teatro infantil quanto ao limite temporal estabelecido: período de 2000 a 2011.

Ressalta-se, ainda, que os cursos de graduação em Biblioteconomia no Brasil têm carência na matriz curricular de disciplinas sobre Arte, Literatura, Poética e isso dificulta a compreensão do alcance da expressividade na vida humana. Os egressos têm o olhar voltado para o teatro na educação, focado na aprendizagem e não na experiência estética, pois intentam (principalmente o bibliotecário escolar e o de bibliotecas públicas) educar, auxiliar na pesquisa, desenvolver a cognição, incentivar a cidadania e induzir à reflexão. Tudo isso é válido e meritório, mas permanece a lacuna de apresentar o objeto artístico pelo ludismo em si, pelo prazer que proporciona, pela sedução do ficcional. Nos Programas de Pós-Graduação em 
Ciência da Informação também se destaca a informação tecnológica e esquece-se da informação literária, como se tal fosse inferior, de segunda categoria.

Concluiu-se: os profissionais da informação não estão plenamente cientes do impacto da dramaturgia no imaginário infantil e há necessidade de reforçar o papel do teatro na satisfação das necessidades estéticas das crianças. Está na hora de repensar as necessidades do ser humano em formação. E lembrar que a arte sempre foi precursora da ciência, da técnica e da tecnologia.

\section{REFERÊNCIAS}

ARAÚJO, Eliany Alvarenga; DIAS, Guilherme Atayde. A atuação profissional do bibliotecário no contexto da sociedade de informação: os novos espaços de informação. In: Oliveira, Marlene de (Coord.) Ciência da Informação e Biblioteconomia: novos conteúdos e espaços de atuação. Belo Horizonte: Ed. UFMG, 2005. p.111-122.

ARCOVERDE, Silmara Lídia Moraes. A importância do teatro na formação da criança. 2008. Disponível em: < http://www.pucpr.br/eventos/educere2008/anais/pdf/629.pdf > Acesso em: 15 jan. 2015.

ARISTÓTELES. Arte poética: texto integral. Tradução de Pietro Nassetti. São Paulo: Martin Claret, 2006.

CANDIDO, Antonio. Literatura, espelho da América? Luso-brasilian Review, Madison, v. 32, p. 15-22, 1995.

CUNHA, Murilo Bastos da. A biblioteca do bibliotecário. 2010. Disponível em: <http://www.ofaj.com.br/colunas conteudo.php?cod=553 >. Acesso em: 16 fev. 2015.

FARIAS, Christianne Martins; VITORINO, Elizete Vieira. Competência informacional e dimensões da competência do bibliotecário no contexto escolar. Perspectivas em Ciência da Informação, Belo Horizonte, v. 14, n.2, p. 2-16, maio/ago. 2009. Disponível em: <http://portaldeperiodicos.eci.ufmg.br/index.php/pci/index>. Acesso em: 20 mar. 2015.

FERREIRA, Taís. A escola no teatro e o teatro na escola. 2. ed. Porto Alegre: Mediação, 2010 .

GIRALDO GIRALDO, Yicel Nayrobis; ROMÁN BETANCUR, Gloria Elena. La biblioteca pública como mediadora em la construcción de la cidadania. Em Questão, Porto Alegre, v. 17, n. 1, p., 211-230, jan./jun. 2011.

GRAZIOLI, Fabiano Tadeu. Teatro de se ler: o texto teatral e a formação do leitor. Passo Fundo: Ed. Universidade de Passo Fundo, 2007.

MARTINS, Maritza Silveira; CIPOLAT, Sabrina. O bibliotecário como agente socializador na disseminação da informação sobre meio ambiente: relato de experiência. Biblos, Rio Grande, v. 18, p. 179-187, 2006. 
MARTINS, Ronaldo. O retrato da Ciência da Informação: uma análise de seus fundamentos sociais. Encontros Bibli: R. Eletr. Ci. Inf., Florianópolis, n. 23, 1․ Sem. 2007, p. 133-150. Disponível em: < https://periodicos.ufsc.br/index.php/eb/article/view/1518-2924.2007 v12n23p133/400 > Acesso em: 06 fev. 2015.

MENDES, Miriam Garcia. A dança. 2. ed. São Paulo: Ática, 2001.

SARACEVIC, Tefko. Ciência da informação: origem, evolução e relações. Perspec. Ci. Inf., Belo Horizonte, v. 1, n.1, p. 41-62, jan./jun. 1996.

SILVA, Vera Lucia Potthoff da. Jogos teatrais. Revista do Professor, Porto Alegre, v. 23, n, 90, p. 12-13, abr./jun. 2007.

SIQUEIRA, Denise da Costa de Oliveira; ALVES, Roberta de Souza Arcoverde. Corpos, utopias: dança e teatro como alternativas de comunicação e cidadania. Em Questão, Porto Alegre, v. 14, n.1, p. 63-77, jan./jun.2008.

SUNDERLAND, Margot. O valor terapêutico de contar histórias: para as crianças, pelas crianças. Tradução de Carlos Augusto Leuba Salum; Ana Lúcia da Rocha Franco. São Paulo: Cultrix, 2005.

VALENTIM, Marta Lígia Pomim. Formação: competências e habilidades do profissional da informação. In: .(Coord.). Formação do profissional da informação. São Paulo: Polis, 2002. p.117-132.
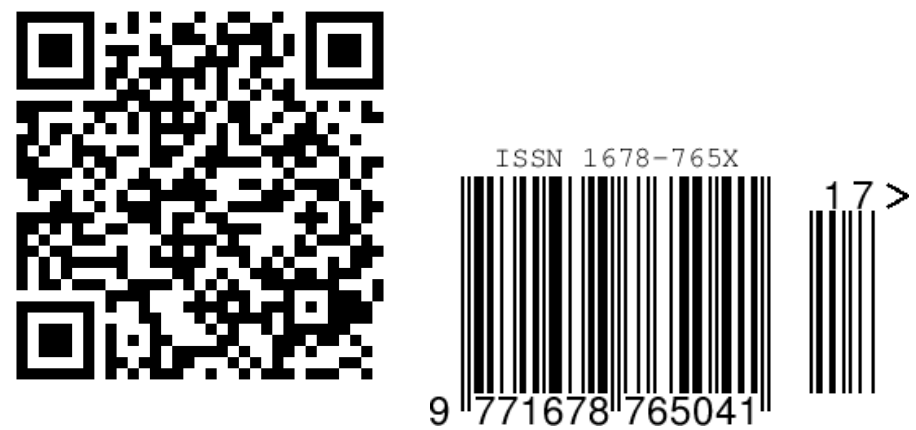